\title{
Sickness Certification Behavior amongst Primary Care Physicians: A Descriptive Analysis of Indirect Measures Using the Theory of Planned Behavior
}

\author{
Yogarabindranath Swarna Nantha ${ }^{1,2, *}$, Arvinder-Singh $\mathrm{HS}^{1,3}$ \\ ${ }^{1}$ Primary Care Research Initiative and Methods Education Department (PRIMED), Seremban Primary Care Clinic, Seremban, Malaysia \\ ${ }^{2}$ Monash University Malaysia, Subang Jaya, Malaysia \\ ${ }^{3}$ Research Centre (Perak), Raja Permaisuri Bainun Hospital, Ipoh, Malaysia
}

Background: The provision of sick leave to patients in general practice often entails a complex decision-making process. Commonly, general practitioners believe that the act of providing sick leave can become confrontational. We assessed the intention, attitude, subjective norm, and perceived behavioral control of general practitioners in relation to sick leave provision at public health clinics in Malaysia.

Methods: A cross-sectional study design was implemented using data from 86 primary health care clinics in two states in Malaysia from February 2014 to March 2015. A questionnaire that comprised indirect measures were developed on the basis of the Theory of Planned Behavior. The questionnaire assessed several dimensions related to sickness certification provision viz., intention, attitude, subjective norm, and perceived behavioral control.

Results: The mean scores in this study revealed that physicians acknowledged that patient factors such as clinical symptoms (6.59 \pm 0.04$)$, debilitating signs and symptoms of diseases (6.45 \pm 0.06$)$, importance of illness recovery (6.07 \pm 0.07$)$, and approval of employers (5.35 \pm 0.09$)$ played an important role in their decision to provide sick leave. Conclusion: The act of providing sickness certification to patients is a complex decision-making process. The findings of this study can be used to devise a targeted intervention to reduce the conflict that physicians face in issuing sick leaves.

Keywords: Sick Leave; Primary Health Care; Health Behavior

Received: April 17, 2018, Revised: April 30, 2018, Accepted: May 17, 2018

${ }^{*}$ Corresponding Author: Yogarabindranath Swarna Nantha https://orcid.org/0000-0002-0207-5490

Tel: +60-67679297, Fax: +60-67679317, E-mail: yogarabin@gmail.com 


\section{INTRODUCTION}

The need to provide patients with sick leaves is a decision most general practitioners (GPs) make on a daily basis. ${ }^{1-4)}$ Studies in various countries reported that physicians were reluctant to perform the role as a gatekeeper in the provision of sick leaves. ${ }^{3,5-14)}$ Physicians often face conflict with patients in the process of providing sick leaves, which ultimately leads to emotional strain at the workplace. ${ }^{5,6)}$

Sick leaves amounts to nearly 4.04 working days lost per worker in Malaysia. ${ }^{15)}$ This translates to a loss of more than US $\$ 2.04$ billion in revenue to employers (Ringgit Malaysia 3.92 to US $\$ 1$ ). ${ }^{15)}$ These figures have increased when compared with the trends in previous years. ${ }^{16)}$ Approximately 591,199 man-hours were lost, amounting to $2.83 \%$ of the total working hours in a year. ${ }^{17)}$ Approximately US $\$ 2.30$ billion was lost in 2012 because of the additional cost of labor and salary paid because of sick leaves. ${ }^{18,19)}$ Concurrently, similar trends were observed in sick leave practices in the United Kingdom and other European countries. $^{1,4,6-10,12,13,20)}$ Current circumstances create great potential for sickness certification abuse, thus necessitating an urgent need for intervention. ${ }^{1-6)}$

This study focused on a descriptive analysis of the beliefs (indirect measures) that control sick leave-prescribing behavior among GPs. These findings were derived from a wider study that assessed sickness certification behavior among GPs in Malaysia. ${ }^{21)}$ The objective of this study was to identify areas that could be explored as avenues for targeted intervention to improve sick leave practices among GPs.

\section{METHODS}

This cross-sectional study was conducted within two states (Negeri Sembilan and Selangor) in Peninsular Malaysia to represent both urban and rural population distributions across the country. A crosssectional study design was conducted using data from 86 primary health-care clinics from February 2014 to March 2015. A total of 329 primary care physicians (of the 666 physicians who were invited to participate in the study) were recruited. No details or demographics of non-responders were collected for this study. Standard guidelines for the Theory of Planned Behavior were used to generate and calculate all indirect measures in the questionnaire. ${ }^{22,23)}$ The intention related to a particular behavior is governed by three main constructs, namely attitude, subjective norm, and perceived behavioral control (PBC). ${ }^{1)}$ The questions for all three constructs followed a 7-point extremely undesirable/desirable and not important/important dimension. The mean scores for intention ranged from 1 (strongly disagree) to 7 (strongly agree). The composite scores for attitude and subjective norm ranged from -126 to 126. The composite scores for PBC ranged from -63 to 63 . The reliability of the constructs was satisfactory as determined by a statistical significance of $\mathrm{P}<0.01$ using the Pearson correlation analysis (Table 1).

\section{RESULTS}

\section{Intentions}

The mean scores for the three intention items were $3.71 \pm 0.11$, $3.04 \pm 0.09$, and $2.87 \pm 0.09$. Overall, the primary care physicians intended to provide sickness leaves for patients ( $3.21 \pm 0.07$; range, 1 to 7 ).

\section{Attitude toward Providing Sickness Certification to Patients}

Most GPs valued the idea of providing sickness certification according to the condition of the patient determined through a clinical assessment (6.59 \pm 0.04$)$. They also strongly believed that sickness certification should be provided to patients to allow them to recover from their illness (6.07 \pm 0.07$)$. However, they show slight hesitation in providing sickness certification to patients because it promotes sickness leaveseeking behavior $(5.13 \pm 0.10)$. Physicians appeared to be ambivalent toward the decision to provide sickness certification on the basis of the behavior of patients toward them $(3.97 \pm 0.12)$. The GPs were uncertain about the genuine intention of a sickness leave request $(4.21 \pm 0.10)$ and the reduction of the patient's work productivity caused by sick leave $(3.77 \pm 0.10)$. Overall, GPs had a moderate and positive attitude toward providing sickness certification to patients (26.4 \pm 1.10 ; range, -33 to 87$)$.

\section{Subjective Norm}

The physicians believe that the approval of their patients $(4.81 \pm 0.09)$, superiors (5.13 \pm 0.09$)$, health managers $(4.78 \pm 0.10)$, and employers $(5.35 \pm 0.09)$ were valuable to them. However, they were ambivalent on whether organizational norms influence their decision to provide sickness leaves to patients $(3.96 \pm 0.10)$. The role of colleagues in the sickness leave provision is least valued $(3.29 \pm 0.10)$. On the whole, physicians had a moderately high and positive subjective norm (24.03 \pm 1.65 ; range, -69 to 112).

\section{Perceived Behavioral Control over Providing Sickness Certification to Patients}

Most physicians believed that patient behavior while seeking sickness

Table 1. Reliability and descriptive statistics for the indirect Theory of Planned Behavior scales

\begin{tabular}{|c|c|c|c|c|c|c|}
\hline Scale & No. of items & Mean \pm standard deviation & Min & Max & $\begin{array}{c}\text { Reliability analysis } \\
\text { (test and retest, Pearson r) }\end{array}$ & $\begin{array}{l}\text { Significance } \\
\text { (P-value) }\end{array}$ \\
\hline Attitude & 6 & $26.4 \pm 1.10$ & -33 & 87 & 0.334 & $<0.01$ \\
\hline Subjective norm & 6 & $24.03 \pm 1.65$ & -69 & 112 & 0.490 & $<0.01$ \\
\hline Perceived behavioral control & 3 & $11.67 \pm 0.89$ & -32 & 52 & 0.370 & $<0.01$ \\
\hline Intention & 3 & $3.21 \pm 0.07$ & 1 & 7 & 0.452 & $<0.01$ \\
\hline
\end{tabular}


leave during a consultation can be an unpleasant situation (2.72 \pm 0.09$)$. They also strongly feel that sickness certification should be given to deserving patients who present with debilitating signs and symptoms (6.45 \pm 0.06$)$. They were uncertain if organizational pressure influenced their sickness leave provision behavior $(3.82 \pm 0.11)$. Overall, physicians had a weak but positive PBC toward providing sickness certification to patients (11.67 \pm 0.89 ; range, -32 to 56 ).

\section{DISCUSSION}

This study investigated the sickness certification provision among GPs working in the Malaysian public health-care system. Previous research involving sickness certification in Malaysia appeared to focus on the issues related to counterfeit sickness certification, the loss of manhours, and the loss of revenue to replace diminished man-hours due to sickness certification. ${ }^{16,17,24)}$ However, a recently published article in Malaysia showed that the behavioral beliefs of GPs also influence sick leave provision. ${ }^{21)}$ The study identified attitudes and subjective norms as predictive factors that influence a physician's decision to provide sick leave to patients. ${ }^{21)}$

Most primary care physician appear to adhere to the biomedical philosophy of medical consultation. ${ }^{22,23)}$ Hence, although the intention to provide sickness certification to patients was high, the intention of GPs to do so was governed by the detection of symptoms that matched the biological properties of an illness. This practice seems to be congruent with another study in Singapore where physicians appeared to prescribe sickness certification on the basis of the presenting illness of patients. $^{25}$

The physicians in this study also found that the act of providing sickness certification to patients can often be a challenging situation. Likewise, $6 \%$ of $31 \%$ of Swiss GPs disclosed that the act of prescribing sick leaves can be problematic. ${ }^{1)}$ In addition, $54 \%$ of the participants claimed that they had a dispute with the patient related to the need for sick leave. ${ }^{26)}$ Therefore, it was not surprising that a modest number of sick leaves in Switzerland were prescribed out of fear that the patient will resort to switching GPs if their requests were declined. ${ }^{26)}$ Similarly, in our study, the salient factor that determined the subjective norm construct to provide patients with sick leave was highly influenced by the patient's approval of a primary care physician's practice or consultation.

The indirect measures in this study were limited by the low test-retest reliability value (Pearson $r$ correlation ranging from 0.33 to 0.49 with a P-value of $<0.001$ ) (Table 1 ). This result indicates that the variables assessed in the study contributed only moderately to the overall temporal stability of the questionnaire. Therefore, we hypothesized that the beliefs pertinent to sickness certification by GPs might be influenced by other latent variables not accounted for in this study.

The intention to provide sickness leave to a patient is a complex decision-making process made by a primary care physician on a routine basis. Steps should be taken to assess the role of the biopsychosocial model to help unravel other salient beliefs that can help to attenuate the conflict between physicians and patients during the act of providing a sickness certification.

\section{CONFLICT OF INTEREST}

No potential conflict of interest relevant to this article was reported.

\section{ACKNOWLEDGMENTS}

We thank the director general of health for allowing this publication. We thank the National Clinical Research Centre, Malaysia (NCRC), CRC Perak, and the staff of the State Health Office of Selangor and Negeri Sembilan for their assistance during the formation stage of the research.

\section{ORCID}

Yogarabindranath Swarna Nantha: https://orcid.org/0000-0002-0207-5490 Arvinder-Singh HS: https://orcid.org/0000-0001-9543-4036

\section{REFERENCES}

1. Foley M, Thorley K, von Hout MC. Sickness certification difficulties in Ireland: a GP focus group study. Occup Med (Lond) 2013;63:369-72.

2. Lindholm C, Arrelov B, Nilsson G, Lofgren A, Hinas E, Skaner Y, et al. Sickness-certification practice in different clinical settings; a survey of all physicians in a country. BMC Public Health 2010;10:752.

3. Swartling MS, Hagberg J, Alexanderson K, Wahlstrom RA. Sick-listing as a psychosocial work problem: a survey of 3997 Swedish physicians. J Occup Rehabil 2007;17:398-408.

4. Winde LD, Alexanderson K, Carlsen B, Kjeldgard L, Wilteus AL, Gjesdal S. General practitioners' experiences with sickness certification: a comparison of survey data from Sweden and Norway. BMC Fam Pract 2012;13:10.

5. Bollag U, Rajeswaran A, Ruffieux C, Burnand B. Sickness certification in primary care: the physician's role. Swiss Med Wkly 2007;137:341-6.

6. Engblom M, Nilsson G, Arrelov B, Lofgren A, Skaner Y, Lindholm C, et al. Frequency and severity of problems that general practitioners experience regarding sickness certification. Scand J Prim Health Care 2011;29:227-33.

7. Hussey S, Hoddinott P, Wilson P, Dowell J, Barbour R. Sickness certification system in the United Kingdom: qualitative study of views of general practitioners in Scotland. BMJ 2004;328:88.

8. Krohne K, Brage S. New rules meet established sickness certification practice: a focus-group study on the introduction of functional assessments in Norwegian primary care. Scand J Prim Health Care 2007;25: 172-7.

9. Lofgren A, Hagberg J, Arrelov B, Ponzer S, Alexanderson K. Frequency and nature of problems associated with sickness certification tasks: a cross-sectional questionnaire study of 5455 physicians. Scand J Prim Health Care 2007;25:178-85.

10. Roope R, Parker G, Turner S. General practitioners' use of sickness certificates. Occup Med (Lond) 2009;59:580-5.

11. Von Knorring M, Sundberg L, Lofgren A, Alexanderson K. Problems in 
sickness certification of patients: a qualitative study on views of 26 physicians in Sweden. Scand J Prim Health Care 2008;26:22-8.

12. Meershoek A, Krumeich A, Vos R. Judging without criteria?: sickness certification in Dutch disability schemes. Sociol Health Illn 2007;29: 497-514.

13. Wynne-Jones G, Mallen CD, Main CJ, Dunn KM. What do GPs feel about sickness certification?: a systematic search and narrative review. Scand J Prim Health Care 2010;28:67-75.

14. Hubertsson J, Englund M, Hallgarde U, Lidwall U, Lofvendahl S, Petersson IF. Sick leave patterns in common musculoskeletal disorders: a study of doctor prescribed sick leave. BMC Musculoskelet Disord 2014;15:176.

15. Malaysian Employers Federation. Employees took an average of 4.04 days of sick leave a year 2010. China Press [Internet]. 2010 Dec 10 [cited 2018 Apr 15]. Available from: http://www.mef.org.my/news/mefitn_article.aspx?ID=71\&article=chinapress101210a.

16. Malaysian Employers Federation. MC watch: plan to monitor medical absenteeism through a central repository database. The Sun [Internet]. 2014 Jun 6 [cited 2018 Apr 15]. Available from: http://www.mef. org.my/MEFITN/Sun140606a.pdf.

17. Malaysian Employers Federation. MEF medical benefits \& man-days loss (including absenteeism) survey 2015 [Internet]. Kuala Lumpur: Malaysian Employers Federation; 2015 [cited 2018 Apr 15]. Available from: http://www.mef.org.my/kc/surveysdetails.aspx?ID=15.

18. Indran SK, Gopal RK, Omar A. Absenteeism in the workforce, Klang
Valley, Malaysia: preliminary report. Asia Pac J Public Health 1995;8: 109-13.

19. Saroja KI, Ramphal KG, Kasmini K, Ainsah O, Bakar OC. Trends in absenteeism rates following psychological intervention: preliminary results. Singapore Med J 1999;40:349-51.

20. Shiels C, Gabbay M, Hillage J. Recurrence of sickness absence episodes certified by general practitioners in the UK. Eur J Gen Pract 2016; 22:83-90.

21. Swarna Nantha Y, Wee LH, Chan CM. Assessing predictors of intention to prescribe sick leave among primary care physicians using the theory of planned behaviour. BMC Fam Pract 2018;19:18.

22. Hansen HS, Rosendal M, Fink P, Risor MB. The general practitioner's consultation approaches to medically unexplained symptoms: a qualitative study. ISRN Family Med 2012;2013:541604.

23. Wade DT, Halligan PW. Do biomedical models of illness make for good healthcare systems? BMJ 2004;329:1398-401.

24. Loh I. Cops bust fake MC syndicate. The Star Online [Internet]. 2017 Apr 18 [cited 2018 Apr 15]. Available from: https://www.thestar.com. my/news/nation/2017/04/18/cops-bust-fake-mc-syndicate/.

25. Ng DC, Lew YJ, Koh EY, Nguyen VH, Wong HB, James L, et al. Sickness certification in Singapore's public primary healthcare system: a crosssectional analysis. Proc Singapore Healthc 2017;27:167-74.

26. Kedzia S, Kunz R, Zeller A, Rosemann T, Frey P, Sommer J, et al. Sickness certification in primary care: a survey on views and practices among Swiss physicians. Swiss Med Wkly 2015;145:w14201. 